\title{
A review of optical techniques for coral monitoring \& introducing low-cost hyperspectral imaging.
}

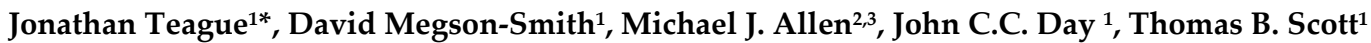 \\ 1 Interface Analysis Centre (IAC), HH Wills Physics Laboratory, Bristol University, Tyndall Ave, Bristol BS8 \\ $1 \mathrm{TL}$ \\ 2 Plymouth Marine Laboratory (PML), Prospect Place, The Hoe, Plymouth PL1 3DH \\ 3 College of Life and Environmental Sciences, University of Exeter, Geoffrey Pope Building, Stocker Road, \\ Exeter, EX4 4QD, UK \\ * Correspondence: jt16874@bristol.ac.uk
}

\begin{abstract}
Monitoring the health of coral reefs is essential to understand the damaging impacts of anthropogenic climate change. Non-invasive methods to survey coral reefs are the most desirable and optics-based surveys, ranging from simple photography to multispectral satellite imaging are well established. Herein, we review these techniques, focusing on their value for coral monitoring and health diagnosis. A new, low-cost hyperspectral imaging technique using linear variable filters is also described. This system is capable of simultaneously producing hyperspectral and photogrammetric outputs, which provides integrated information of reef structure and physiology.
\end{abstract}

Keywords: Coral reef monitoring; Reef health; Review; Hyperspectral Imaging; Marine optics;

\section{Introduction}

Coral reefs are strategically important for coastal nations in tropical and subtropical regions due to the valuable ecosystem goods and services they provide [1]. However, these reef systems are now being impacted on a global scale by a variety of conditions, namely: "coral bleaching" [2], [3], diseases [4], [5], nutrient pollution [6] and algal overgrowth [7], coastal engineering [8] and sedimentation [9], crown-of-thorns [10] and sea-urchin predation [11]. Corals are particularly susceptible to environmental changes as they have low tolerance to variations in temperature, salinity and solar radiation [12]. Sustained periods of stress can lead to coral colony death, and, in some instances, to whole reef collapse [13]. This represents a significant concern for the 275 million people who live within $30 \mathrm{~km}$ of these ecosystems, and who rely on these reefs for their livelihoods and food security [14].

Anthropogenic climate change has been identified as the main cause of the ongoing global coral decline [15]. Analysis by the Intergovernmental Panel on Climate Change (IPCC) using representative concentration pathway (RCP) models RCP4.5 \& RCP8.5, indicates that as of 2020 over $90 \%$ of global reef locations will have experienced some degree of increased susceptibility to disease and bleaching as a result of climate change [16]. Using the more conservative RCP4.5 model, studies suggest that rapid coral recovery after bleaching events may be possible up to the year 2100 [17]. However, using a more moderate model, such as RCP6.0, indications suggest that coral populations may only have a 50:50 chance of recovery over total collapse [17]. Under the "business-as-usual" scenario (RCP8.5), with accelerating temperature change and recurring bleaching, coral recovery is considered unlikely [17]. As such, monitoring and protection of these valuable natural assets is an internationally important endeavour.

Globally, climate-driven bleaching events have frequently coincided with El Niño-Southern Oscillation (ENSO) events, because tropical sea surface temperatures (SST) are generally warmer during ENSO years [18]. As an effect of global warming, SSTs 
during La Niña conditions are becoming warmer than those observed during typical El Niño events 30 years ago [18]. All models [17] indicate that as global climate change progresses, SST will continue to rise along with the number and frequency of extreme heating events, causing increased bleaching on coral reef systems. Two thirds of the recorded global scale bleaching events have occurred within the last decade, in 2010 and then during 2014-2017 [19], [20].

While coral bleaching is most commonly associated with changes in SST [3], [21], it can also be a response to other external factors or triggers, such as ocean acidification [22], bacterial infection [23] or shading caused by extreme turbidity [24]. The term 'bleaching' refers to the loss of the symbiont algal cells of the family Symbiodiniaceae, which are normally the main provider of coral colour [25], [26]. The white or bleached appearance of the coral results from the calcium carbonate exoskeleton becoming visible, since the coral tissue itself is translucent [25].

Coral disease is another of the main causes of reef degradation and has been increasing worldwide since first studied in the 1970s in the Red Sea [27]. It has become particularly prevalent in the Caribbean [28], [29], but has also been increasingly recorded on other reef systems, such as the Great Barrier Reef [4], [28], [30], [31]. Coral can be more susceptible to disease due to other factors such as declines in water quality and fish stocks, heat stress and, more recently, to ocean acidification driven by anthropogenic activity [32]-[34]. In some cases, specific pathogens have been identified as a primary contributor [28], [35]. A diverse array of diseases has now been observed with approximately 30 diseases and syndromes affecting the health of 150 different species worldwide [5], [36]. The term 'disease' is used to describe symptoms arising from a known pathogen, while 'syndrome' refers to effects arising from an unknown causative agent, whether it be a pathogen, pollutant or climate condition such as ocean warming [25].

Visible changes associated with coral ill-health can provide a valuable metric for the monitoring of colonies. Affected corals are frequently characterised by abnormal or decreased pigmentation in compromised tissue [37]. White, brown, pink, yellow and black line diseases are all recognised [32]-[34], [38] based on the alteration of colour caused by the disease.

Bleaching or disease is often identifiable by the absence of specific pigments in individual corals [39]-[42]. These pigments have specific wavelength peaks characteristic of their optical reflectance or fluorescence spectra. These pigments include: Chlorophyll-a absorption (676 nm) [43], Chlorophyll-a fluorescence (685 nm), Peridinin (574 nm) [44], Diatoxanthin (607 nm) [44], and green fluorescent protein (GFP) (511 nm)[45].

The photosynthetic pigment chlorophyll-a and accessory pigments peridinin, and dinoxanthin provide a direct insight into the symbiont density [46], [47]. As these pigments are only found within corals' symbiotic partner Symbiodiniaceae they provide a direct bleaching indicator. GFP's fluorescence provides a different insight as it is highly responsive to thermal fluctuations [21], [48], [49] and is often spectrally more distinctive, namely in its intensity when compared against chlorophyll fluorescence [39].

This observed specificity lends itself to utilising automated image-based techniques that can objectively quantify and monitor compromised colonies based upon spectroscopic optical measurements. Current observations by human divers are necessarily subjective and provide less robust or detailed data.

\section{Current Optic Based Methods For Monitoring Coral Health}

There are many factors relevant to the accurate monitoring of coral reefs. These may be: biological, including abundance of coral predators, coral species composition and distribution; chemical, such as $\mathrm{pH}$ (acidity) or the presence of nutrients; physical parameters such as temperature and turbidity and socio-economic parameters such as marine protected areas and fishing communities [50]. This review will focus on the biological parameters. 
Many current reef health survey methods employ divers as 'observers'. The advantages of this are that they offer a versatile set of skills for coral monitoring, being highly maneuverable, adaptable and able, with training, to deliver reasonably precise results. Observers generally record basic data, such as 'percentage cover of live coral', which is the most widely used metric of coral reef condition and is commonly used in studies that record coral reef decline and recovery across local spatial scales [51]. A drawback is that such surveys are time-consuming and so are often not able to prioritise disease identification and assessment [4], [29], [52], [53]. A standardised survey for assessment of coral health requires detailed examination of all coral colonies within a designated sample area (e.g. transects or quadrats), and so also involves lengthy and expensive person-intensive field time [54].

Underwater diver-generated photographic surveys employing photo-quadrats or video transects comprise the bulk of modern reef monitoring activities and may be used to record the reef substrate over hundreds of square metres. Due to difficulties associated with conducting frequent surveys over large areas by divers, there is an increasing use of 'robotic observers', i.e. unmanned underwater vehicles (UUV's) that can be used to cover thousands of square metres [55], [56]. The increased area coverage and data generation offered by UUV's allows the time and human effort otherwise required for physical measurements to be better used for processing, interpretation and analysis of the often semi-quantitative digital data.

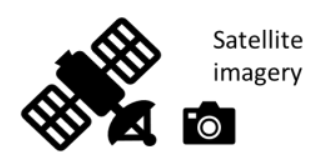

imagery

Aerial based Aerial based
surveys

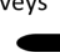

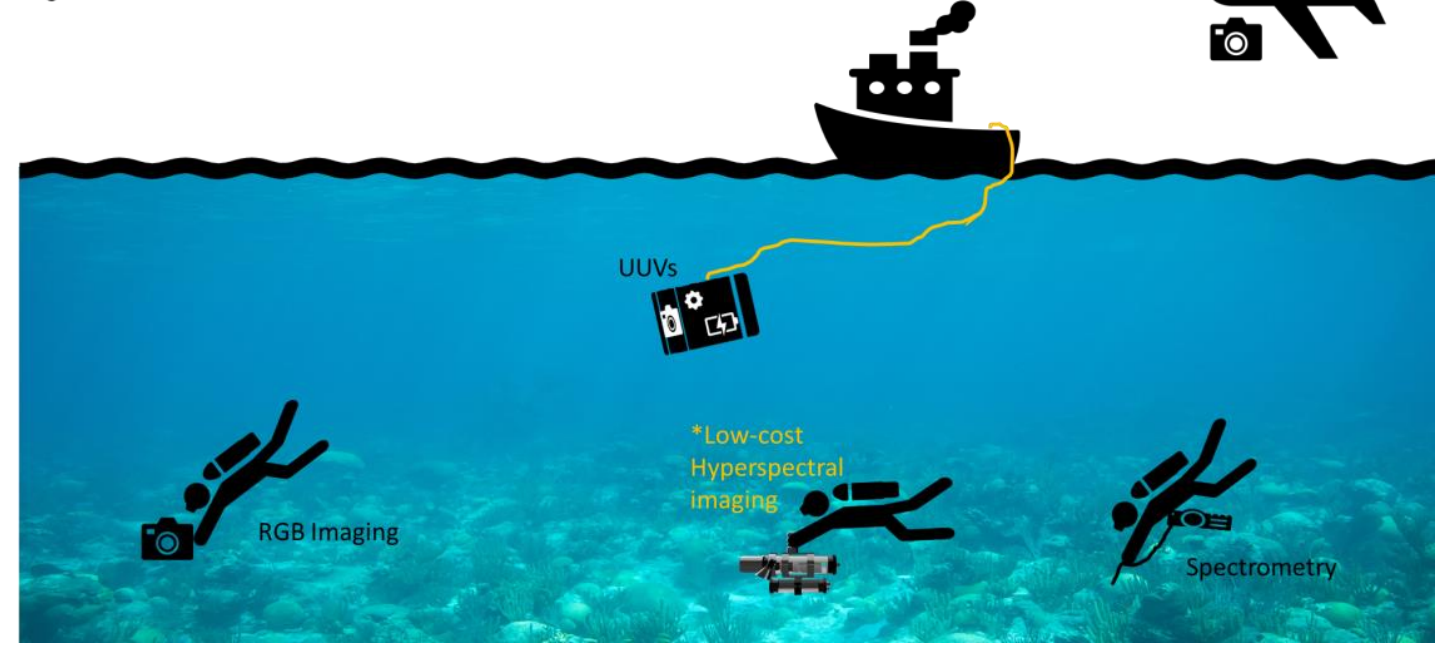

Figure 1. An overview of the current optical techniques from satellites to underwater systems.

A major advantage of image-based surveys is that the images created provide a permanent digital record of the habitat at the time they were taken. This reduces the dependency on in-field coral experts and provides data that can be re-analysed retrospectively or compared directly between repeat surveys. The following section describes diver-based optical survey techniques, which represent the 'classical' approach to coral surveyance. Many of these techniques could readily be employed using UUVs, but as yet, have found limited application in this manner. 
Traditional cameras used in digital photography detect light in three broad colour channels: red, green, blue (RGB), centered at approximately $660 \mathrm{~nm}, 520 \mathrm{~nm}$ and $450 \mathrm{~nm}$ respectively. This enables similar images to be taken to those perceived by the human eye, which also sees using only these RGB channels [57]. Cameras can be employed in many coral reef surveying techniques such as photo-quadrat sampling in which quadrats are imaged via high resolution digital cameras. This secures a visual record suitable for subsequent laboratory analysis as opposed to manual in-situ coverage estimates. Imaging thus allows a reduction in diver 'bottom time' as compared with non-image based surveyance. The advantage of laboratory analysis is that it allows images to be run through machine learning software, such as CoralNet [38], which attempt to fully or partially automated classification and benthic cover estimates. However, classification can only be made after sufficient training data is provided to the algorithm [58], [59]. These types of machine learning systems are still in their infancy and to-date can only effectively estimate the cover of common coral genera.

Images can also be interpreted to provide rudimentary colour analysis. This yields outputs similar diver assessments undertaken qualatively, by eye using colour charts or wheels. The comparison of corals against known colour hues corresponding to different concentrations of symbionts [60] enables divers to quickly identify the extent of any coral bleaching, though other aspects of coral health may be overlooked. Performing such surveys using traditional digital camera (RGB) images is an improvement, since the intensity of individual colour channels can be recorded and interpreted. For example, the intensity of red wavelengths indicates the extent of chlorophyll absorption [61]. However, the value of the method is limited as only 3 broad colour bands are recorded by the camera sensor. The method can aid in preliminary assessments of bleaching, but by the point bleaching is RGB-detectable, around $70 \%$ or more of its symbionts have been expelled [62]. A general point to remember is that these types of survey typically only cover an individual coral colony and may not be representative of the whole reef system. They also only provide a snapshot of an environment and cannot be extrapolated to an understanding of the ongoing population dynamics of the whole reef system.

An emerging and more advanced utilisation of RGB imaging is for the creation of three-dimensional (3D) reconstructions of coral systems via photogrammetry. With recent advances in photogrammetric processing this is now relatively quick and easy to conduct [63]. Photogrammetry uses digital cameras, to take a set of overlapping images of a target area. Ideally adjacent images should have $60-80 \%$ overlap [64]. Physical parameters can be obtained from 3D models of coral reefs, such as surface topography, estimations of rugosity and surface area, as well as coral cover and distribution [65]. Crucially, a wide range of additional information can be extracted from the same original data set, making it a useful analysis technique when images sets are recorded. However, when using standard digital cameras, the method is still limited. Resultant images are only sensitive to changes in for coral colour or fluorescent emissions as detected by the three RGB channels.

\section{Spectroscopic Techniques}

Spectroscopic techniques can image in numerous, narrower wavelength bands across the whole visible light spectrum and marks an improvement over simple RGB imaging. The use of spectral data enables a more definitive discrimination between live coral, macroalgae and other photoactive organisms by using the specific spectral "signature" or "fingerprints" associated with a certain organism or type of organism [66], [67]. It also identifies if corals are displaying a decline from 'normal health' by measuring the relative intensity of the spectral signatures arising from specific pigments associated with health, such as chlorophyll. This can be achieved by using reference targets to correct for incident light variations, thereby normalising spectra so it can be compared between datasets to track changes in pigment intensity and thus bleaching. 
Underwater spectrometry can be achieved by using laboratory spectrometers enclosed in waterproof housings, with fibre optic probes to record radiance reflectance measurements. The fibre optic probes are held at an orthogonal angle to the solar incidence angle, approximately $0.5-1.0 \mathrm{~cm}$ from the target [42]. An accompanying reference measurement is required to normalise for variations in ambient illumination. This is achieved by making a reflectance measurement from a well characterised, white Lambertian reflectance target such as Polytetrafluorethylene (PTFE) or a Spectralon (Labsphere, USA). The reference spectrum enables a correction function to be applied to the data. Specialised spectrometers can also be employed for certain niche applications. For example, pulse amplitude modulation (PAM) fluorometers specifically look at fluorescence to determine the amount of chlorophyll present. Chlorophyll density can be used to determine relative electron transport rates of photosynthetic organisms to provide a measurement of photosynthetic efficiency [68]. This is a measure of how well chlorophyll converts light into energy and detects compromised tissues that will be less efficient. The diving PAM I \& II (Walz, Germany) are examples of underwater fluorometers and are the most commonly used devices in studies using this technique [3], [69], [70]. PAM devices do have limitations. Notably, a requirement for the sampling optical fibre probe to be held in near contact $(<5 \mathrm{~mm})$ with the sampled object for a long time $(>30 \mathrm{~s})$ to obtain accurate readings. Generally, an irradiance sensor is used in conjunction with the sensor probe to obtain an incident light reference. However, in practice to simultaneously align the sensors on the coral whilst taking a measurement can be challenging.

Spectrometers and fluorometers are able to generate more accurate spectral data but they also suffer from many of the same pitfalls as RGB imaging. Data acquisition is typically slow, when used to cover a whole reef system. This is mainly due to the small sampling area of the probes and the requirement to make point measurements. This limitation makes the technique particularly unsuitable for large-area surveys. Additionally, multiple points are often sampled on individual corals to obtain average spectra. However, the small number of measurements precludes confidence that these average spectra are truly representative of the whole organism or a whole reef system.

Conversely, spectroscopy techniques using imagers (multispectral and hyperspectral imaging) can generate spectra for every pixel in an image within one data acquisition. This makes the process of data collection quicker and more efficient, thereby facilitating the collection of data sets that are more comprehensive and representative. In turn, imagers can categorise and quantify colour. Spectral imagers generally comprise a dispersive element (either a prism or diffraction grating) or filter, which splits or filters incoming light into wavelengths, and an imaging detector, such as a charged coupled device (CCD) or complementary metal-oxide-semiconductor device (CMOS).

Multispectral imagers record data across multiple spectral bands. This is usually between between 3 and 15 spectral bands [71]. Conversely, hyperspectral imaging records in hundreds of spectral bands, which means data may be collected and processed across the whole visible and/or near infrared spectrum with improved spectral resolution.

Previously, some multispectral systems have been deployed to assess specific marine monitoring cases. These included determining coral fluorescence using narrow bandpass filters [72] and filter wheel style imagers for classification via spectral discrimination [73]. Other imagers have been produced for applications such as the exploration of marine minerals and ores [74] but are not currently being used in coral monitoring surveys [75].

Underwater Hyperspectral Imaging (UHI) is a relatively new, emerging technology with limited published instances to date. Current diver operated hyperspectral systems such as the "HyperDiver" system [76], can generate hyperspectral and traditional RGB images simultaneously capturing synchronised high-resolution digital images, hyperspectral and topography data [76]. The system utilises a push-broom hyperspectral im- 
ager (Pika 2, Resonon Inc., USA) with a spectral range of 400-900 nm sampled at $\sim 1.5 \mathrm{~nm}$ resolution with 480 fixed bands and 640 spatial pixels [76].

Push broom or line scanning imaging methods acquire full spectral data one spatial line at a time. The line is imaged onto the entrance slit of a spectrometer which disperses the light into its spectral components before reaching the sensor array. The composite image is constructed by either moving the slit across the image plane, or by moving the entire system across the scene [77]. This is advantageous as spectral data can be gathered whilst the imager is moving, which provides both full spectral and spatial data. Other hyperspectral systems such as 'Full data cube snapshot' imagers work from fixed view points, similar to traditional RGB imagers. In this case a push broom effect is achieved by optically scanning a linear field of view across the hyperspectral detector within the device. The need for a stable platform and the delicate nature of the optics involved make them generally unsuitable for use in UHI.

UHI presents additional potential applications using an 'objects of interest' (OOI) identification technique, as described by Johnsen [78], which include: mapping and monitoring of seafloor habitats for minerals or soft versus hard bottom; seafloor pipeline inspections to determine type of material, cracks, rust and leakage; shipwrecks (type and state of wood, nails, rust and artefacts); deep-water coral reefs and sponge fields for species identification, area coverage and physiological state, and kelp forests (species identification, area coverage, physiological state and growth rates of benthic organisms).

Current UHI technologies (outlined in table 4) are generally bulky systems which are difficult to deploy and maneuver. For example, the "Hyperdiver" system [76], including all its additional sensors and payloads, weighs $\sim 32 \mathrm{~kg}$ in air. Other sensors, specifically the tunable LED-based underwater multispectral imaging system (TuLUMIS) and ocean vision (UHI OV), are designed to be mounted on a UUV. The UUV provides the interface system to operate the camera as well as a translation platform. These are not easily deployed by a diver.

The use of UUV's does however eliminate the limitations imposed by diver reliance. For example, dive surveys require substantial amounts of time as there is a finite period a diver can spend underwater, on dives this is usually dependent on air-tank capacity and depth. Subsequent dives can be achieved through the use of multiple air-tanks but ultimately a diver will fatigue. The corresponding issue on UUV based surveys is battery life, although multiple batteries can be used to extend surveying time. Crucially, UUV's do not suffer fatigue and can be deployed longer than their human counterparts. A UUV can also cover a larger distance in a shorter time. For example, a 120 metre squared area may take two scuba divers up to 2.5 hours [4], equating to a surveying rate of $0.13 \mathrm{~m}^{2} / \mathrm{s}$. Comparatively, a low-cost remotely operated vehicle (ROV) such as BlueROV2 can achieve survey rates of $1 \mathrm{~m}^{2} / \mathrm{s}$. A key limitation to both divers and UUVs is repeatability and accuracy when surveying reefs because Global Positioning System(s) (GPS) do not work underwater. Acoustic transponder networks designed for UUVs create a way of translating GPS coordinates underwater and thus improve repeatability and accuracy by recording an accurate georeferenced data [63].

The use of UHI on UUV's is currently limited with only a few studies having been reported. One such study [79], used a prototype UHI system for mapping the seafloor for the automated identification of seabed, habitat and OOI in coral reefs. Other studies [67] specifically using hyperspectral imaging with corals, have mainly focused on coverage and benthic discrimination with machine learning to classify corals. They have not focused on assessing health or disease. The current generation of commercially available hyperspectral imagers are often cost prohibitive both to acquire and to insure for marine studies. Consequently, there exists a need for technology development and application to study marine environments such as the surveyance of coral health. 
Data on coral can also be gained remotely using time-lapse satellite or aerial imagery combined with spectral discrimination. However, this approach is usually only able to discriminate between coral colour types and broad benthic communities, and not between coral species [33]. This section describes remote sensing techniques, which represent the more modern approach to global coral surveyance.

\section{Airborne Multi/Hyperspectral Imaging}

Imaging techniques can be deployed above the water's surface using multispectral/hyperspectral imagers. These surveys primarily look at coral distribution. However, they are limited by low spectral and spatial resolution and are only able to distinguish between coral, algae and sand [67]. Aerial surveys can be undertaken using light aircraft or helicopters flying at an altitude of approximately $150 \mathrm{~m}$. Aircraft and satellites can be equipped with multispectral and hyperspectral imagers. Aircraft are able to use benthic reflectance signatures to map the composition and condition of shallow water ecosystems in higher spatial resolution than their satellite counterparts, albeit at the cost of lower spatial scale [80]. In bleaching surveys each reef is typically assigned a number from zero to four, these categories are associated with bleaching severity. The category classifications are as follows: CAT $0,<1 \%$ of corals bleached; CAT 1, 1-10\%; CAT 2, 10-30\%; CAT 3, 30-60\%; and CAT 4, $>60 \%$ of corals bleached [81]. Correction algorithms are required to account for loss of light through factors such as atmospheric scattering and the attenuation coefficient of water. As such, airborne surveys still require underwater ground-truthing to compare and validate these correction procedures[18].

The spatial resolution and cost of remote hyperspectral observations can be further improved by using unmanned aerial vehicles (UAVs). Lightweight hyperspectral cameras deployed on UAVs typically produce images with a spatial resolution of around 15 $\mathrm{cm} /$ pixel, allowing for the identification and monitoring of individual corals [82]. In a set period this method can cover larger areas than diver or UUV solutions. Compared to manned aircraft, UAVs achieve higher resolution due to the lower flight altitude (30-100m) but at a smaller spatial scale. This technique allows for rapid data collection. For example, a 2017 study by Queensland University of Technology demonstrated that a UAV could photograph 40 hectare of coral reef in about 30 minutes to study coral bleaching [19].

\section{Satellite Multi/Hyperspectral Imaging}

The loss of pigmented Symbiodiniaceae from corals during mass bleaching events results in an optical signal that can be strong enough for detection by remote sensing satellites in low Earth orbit. Satellite systems allow the surveys to cover vast areas quickly with around 30,000 km2 acquired in a 5-hour period, with a spatial resolution of $30 \mathrm{~m}[83]$.

Global programs such as the coral reef watch by the national oceanographic and atmospheric administration (NOAA), use satellite technology to observe and monitor reef conditions across all visible reefs. Although in practice it is mainly limited to shallow reefs which are less than $25 \mathrm{~m}$ deep. Satellites are used to-estimate SSTs and predict the potential extent of coral reef bleaching [20]. Temporal data can be used to monitor the effect of SST anomalies on coral [84]. During the warmest months of the year, often a $1^{\circ} \mathrm{C}$ elevation above the monthly mean maximum can be associated with bleaching events [85]. Coral Reef Watch's HotSpot program uses these satellite observations to give a "Satellite Bleaching Alert" or SBA [86]. Coral Reef Watch issues four levels of SBA for 24 reef sites in the tropics [87] based on satellite near-real-time HotSpot levels. This gives an early warning system for vulnerable coral reef systems determined by the change in SST from the norm. The technique, however, is largely speculative as there is no actual data taken directly from the corals themselves. It should therefore be considered a top-level predictive tool for bleaching events.

Other satellites equipped with multispectral cameras can be used to monitor coral condition. The Landsat Thematic Mapper (TM) carried by Landsats 4 and 5 has mapped 
the geomorphology of Australia's Great Barrier Reef [88]. The Landsat TM and Enhanced Thematic Mapper Plus (ETM+) have been used to monitor changes in groups of coral reefs [89]. More recently, a detailed survey of reefs near the Nansha Islands in the South China Sea was conducted using the Landsat 8 operational land imager (OLI) [90]. Specialised, marine focused remote sensors have also been deployed. In 2009, the Hyperspectral Imager for the Coastal Ocean (HICO) was installed on the International Space Station [91]. HICO focused on selected coastal regions and imaged them with full spectral coverage (380 to $960 \mathrm{~nm}$ sampled at $5.7 \mathrm{~nm}$ intervals). During its five years in operation HICO collected over 10,000 scenes from around the world [92].

Both airborne systems and instruments deployed in low-Earth orbit provide the ability to conduct large area reconnaissance of coral reef health, albeit with a relatively poor spatial resolution. These systems can image most global shallow reefs but are depth limited and struggle to map deeper reefs [93]. Where light absorption precludes the recognition of features below a critical depth threshold of approximately $20 \mathrm{~m}$ water depth, dependent on water clarity [94], [95]. Any spectral data taken above the water's surface require correction for the attenuation of light through the atmosphere and the water, which are wavelength specific. These corrections vary due to daily conditions and water types each producing variability of the spectral diffuse attenuation coefficient in coral reefs and adjacent waters [96]. Again, ground truthing is required to validate the spectra used for these corrections.

\subsection{Limitations of Non-Invasive Monitoring}

As outlined previously, a variety of data can be collected using these different methods of assessment to indicate coral 'health'. Each technique generally gives multiple metrics that can be used, as summarised in Figures $2 \& 3$.

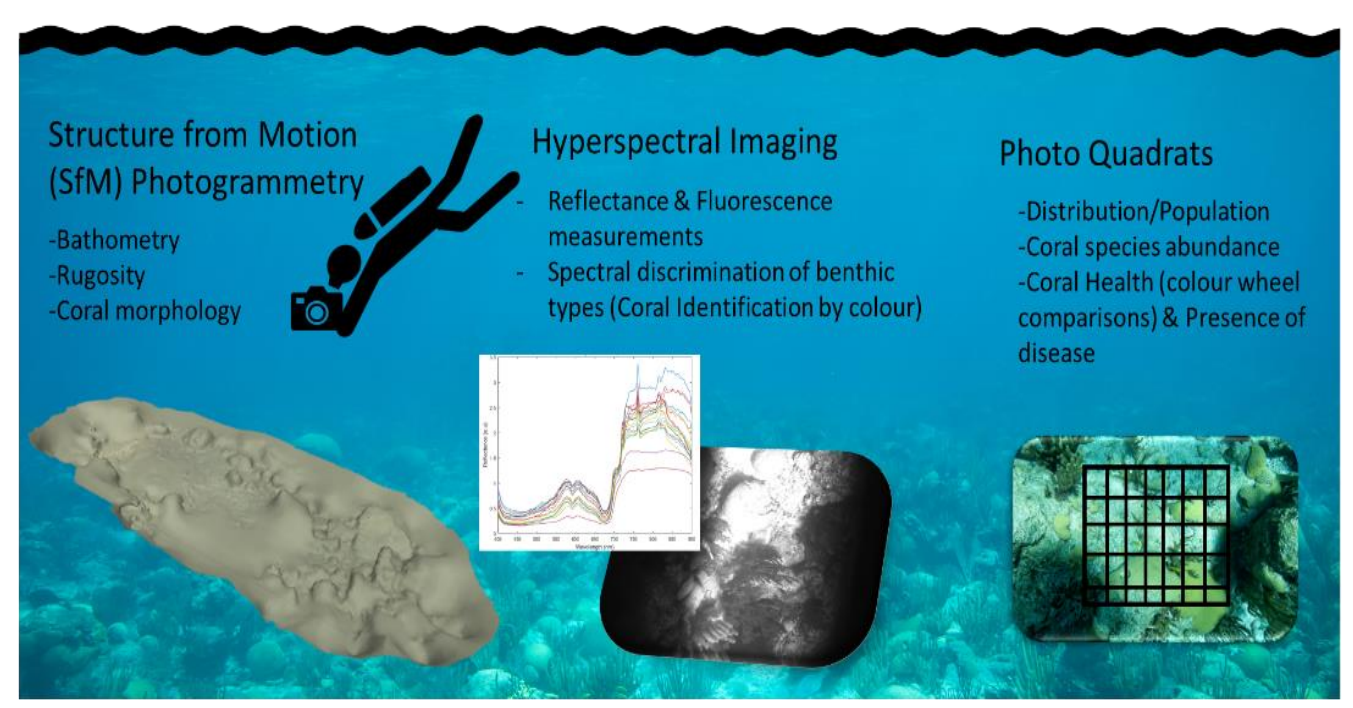

Figure 2. Diver Image based techniques and examples of the type of data produced from the main techniques. 


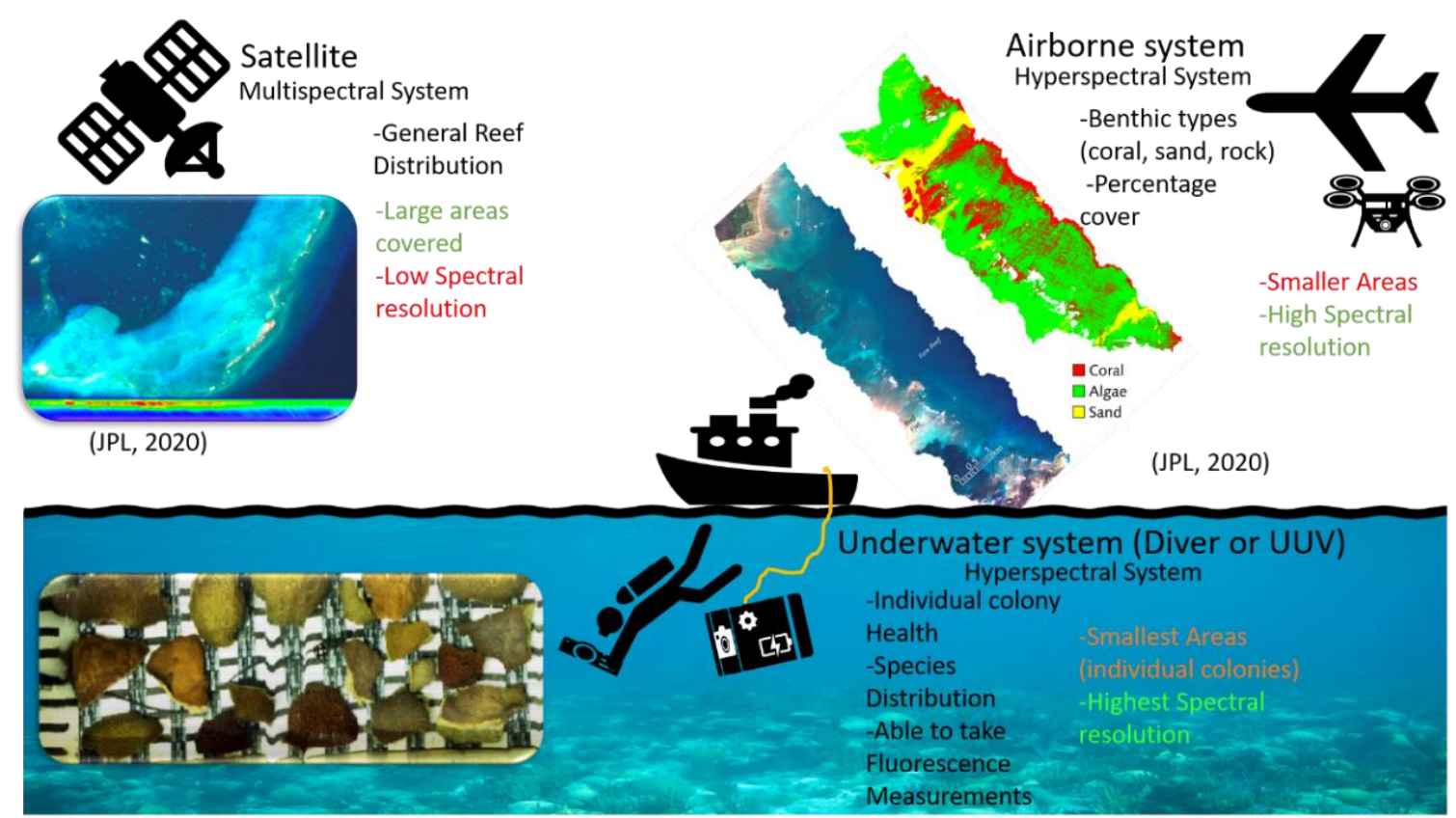

Figure 3. The types of data from each type of spectral system at the different levels from satellites to underwater systems. Images (Jet Propulsion Lab (JPL), 2020) \& (Eric J. Hochberg, Bermuda Institute of Ocean Sciences).

The use of spectral techniques to look at other parameters, such as distinguishing between coral species and identifying diseases and bleaching suffer from limiting factors. These include, phenotypic plasticity in host and symbiont pigment compositions [97] and the physical parameters of the water column [98].

In order to derive meaning from colour and its relation to bleaching, bar a simple colour presence vs absence assessment; exact symbiont density and chlorophyll-a content of individual coral samples need to be quantified. Unfortunately, this procedure is destructive. Typically, whole corals or tissue samples are removed for laboratory analysis. Coral health is assessed based on the composition of extracted Symbiodiniaceae and chlorophyll content [99]. Laboratory bleaching experiments allow links to be made between the effects of bleaching and pigment intensity. These experiments link the levels of symbiont density to spectral peaks and approximate the stage of bleaching that can be determined using in situ hyperspectral imagery [39]. Effective coral monitoring in this way can thus become a victim of itself; effective identification in a plethora of sites featuring the signatures of coral bleaching, creates an insurmountable requirement for downstream laboratory based truthing.

Nevertheless, as outlined in Tables $1 \& 2$, the techniques described have many features that contribute to their overall suitability for coral monitoring including cost, spatial scale, spectral resolution, and any additional data taken alongside sample acquisition. The choice of instrumentation is normally governed by research requirements [100], [101]. The cost of the instrumentation is often the most prohibitive factor in the adoption of improved sensing strategies. For instance, to determine the global extent of coral bleaching, airborne and satellite imagers are best suited despite their cost and problems assessing deep reefs. However as stated, ground truthing data would be required to validate and correct for atmospheric and aqueous attenuation correction algorithms. For in-situ surveys which require high spectral resolution, an underwater hyperspectral system is best suited. This provides the desired spectral resolution at a non-prohibitive cost whilst simultaneously gathering related supporting measurements (See Table 3).

Therefore, the choice of the underwater spectroscopy tool is also crucial. Each imaging technique has a number of defining qualities and tradeoffs regarding spectral 
range, resolution, scale of operation, depth rating and cost. These determine their suitability and effectiveness in any given situation.

Looking towards the future, new spectral tools will emerge to address these issues. A range of underwater imagers identified by Liu, 2020 [75] (Table 4) are compared as well as a new "Bi-Frost" digital single-lens reflex (DSLR) hyperspectral camera system presented in section 3. Whilst spectral performance and cost are key factors, other considerations should be considered. Of particular importance are how the device is interfaced and how portable it is.

Table 1. Optical techniques rated by cost, spatial scale, spatial resolution and additional data gathered.

\begin{tabular}{|c|c|c|c|c|c|}
\hline Technique & Cost & Spatial Scale & $\begin{array}{c}\text { Spatial Res- } \\
\text { olution }\end{array}$ & $\begin{array}{c}\text { Additional Data } \\
\text { Gathered }\end{array}$ & Notes \\
\hline $\begin{array}{c}\text { RGB imaging } \\
\text { (Based on GoPro) }\end{array}$ & Very Low & Moderate & Very High & Photogrammetry & $\begin{array}{c}\text { Limited spectral } \\
\text { data obtained }\end{array}$ \\
\hline $\begin{array}{c}\text { Spectrometers } \\
\text { (Waltz Diving PAM) }\end{array}$ & Moderate & Very Low & Very High & N/A & $N / A$ \\
\hline Bi-Frost DSLR & Low & Moderate & Very High & $\begin{array}{c}\text { Photogrammetry, Flu- } \\
\text { orescence }(\mathrm{HyFi})\end{array}$ & $\begin{array}{l}\text { Night-time im- } \\
\text { aging required for } \\
\text { Fluorescence }\end{array}$ \\
\hline $\begin{array}{l}\text { Current UHI systems } \\
\quad(\text { See table } 4)\end{array}$ & $\begin{array}{c}\text { Moderate to } \\
\text { High }\end{array}$ & Moderate & $\begin{array}{l}\text { Very High to } \\
\text { Moderate }\end{array}$ & $N / A$ & $\begin{array}{l}\text { Often large and } \\
\text { cumbersome or } \\
\text { designed specifi- } \\
\text { cally for UUV's } \\
\end{array}$ \\
\hline $\begin{array}{c}\text { Drone mul- } \\
\text { ti/hyperspectral imag- } \\
\text { ing } \\
\text { [82] }\end{array}$ & $\begin{array}{l}\text { Moderate to } \\
\text { High }\end{array}$ & Moderate & Moderate & $N / A$ & $\begin{array}{l}\text { Requires Ground } \\
\text { truthing }\end{array}$ \\
\hline $\begin{array}{c}\text { Aeroplane mul- } \\
\text { ti/hyperspectral imag- } \\
\text { ing } \\
{[67],[102]}\end{array}$ & High & High & $\begin{array}{c}\text { Moderate to } \\
\text { Low }\end{array}$ & $N / A$ & $\begin{array}{l}\text { Requires Ground } \\
\text { truthing }\end{array}$ \\
\hline $\begin{array}{c}\text { Satellite mul- } \\
\text { ti/hyperspectral imag- } \\
\text { ing } \\
{[103]}\end{array}$ & ${ }^{*}$ Very High & Very High & Very Low & $\begin{array}{c}S S T, R G B \text { images } \\
\text { (Dependant on addi- } \\
\text { tional sensors } \\
\text { equipped) }\end{array}$ & $\begin{array}{l}\text { Requires Ground } \\
\text { truthing }\end{array}$ \\
\hline
\end{tabular}

HyFi: hyperspectral fluorescence imaging, UUV's: unmanned underwater vehicles, SST: Sea surface temperatures. * based on total cost of building and launching into orbit. 
Table 2. Guide to rankings for each classification outlined in Table 1.

\begin{tabular}{cccc}
\hline Classification & Cost & Spatial Scale & Spatial Resolution \\
\hline Very Low & $<£ 1,000$ & $m m-\mathrm{cm}$ & $\mathrm{Km}$ \\
Low & $<£ 5,000$ & $m$ & $<100 \mathrm{~m}$ \\
Moderate & $<£ 10,000$ & $<100 \mathrm{~m}$ & $<10 \mathrm{~m}$ \\
High & $>£ 25,000$ & $k m$ & $\mathrm{~m}$ \\
Very High & $>£ 100,000$ & $100+\mathrm{km}$ & $\mathrm{mm}-\mathrm{cm}$ \\
\hline
\end{tabular}

Table 3. Techniques ability to monitor important criteria as outlined by Leujak \& Ormond, 2007 [101] for coral surveyance.

\begin{tabular}{|c|c|c|c|c|c|c|}
\hline Criteria & $\begin{array}{c}\text { RGB } \\
\text { Imaging }\end{array}$ & Spectrometers & $\begin{array}{l}\text { Bi-Frost } \\
\text { DSLR }\end{array}$ & $\begin{array}{c}\text { Drone Mul- } \\
\text { ti/Hyperspectral Im- } \\
\text { aging }\end{array}$ & $\begin{array}{c}\text { Aeroplane Mul- } \\
\text { ti/Hyperspectral Im- } \\
\text { aging }\end{array}$ & $\begin{array}{c}\text { Satellite Mul- } \\
\text { ti/Hyperspectral Im- } \\
\text { aging }\end{array}$ \\
\hline $\begin{array}{c}\text { Damage (Dis- } \\
\text { ease/Bleaching) }\end{array}$ & Yes & $\begin{array}{c}\text { Yes } \\
\text { (Local Scale) }\end{array}$ & Yes & Yes & $\begin{array}{c}\text { Yes } \\
\text { (Mass Scale })\end{array}$ & $\begin{array}{c}\text { Yes } \\
\text { (Mass Scale })\end{array}$ \\
\hline Recruits & $\begin{array}{l}\text { Yes (modi- } \\
\text { fied cam- } \\
\text { era) }\end{array}$ & No & $\begin{array}{c}\text { Yes } \\
(\mathrm{HyFi})\end{array}$ & No & No & No \\
\hline Number of Colonies & Yes & No & Yes & Yes & Yes (Height Dependent) & No \\
\hline $\begin{array}{c}\text { Growth Measure- } \\
\text { ments }\end{array}$ & Yes & No & Yes & No & No & No \\
\hline Repeatability* & No & No & $\begin{array}{l}\text { Yes } \\
\text { (Reef } \\
\text { Scale) }\end{array}$ & Yes & Yes & Yes \\
\hline
\end{tabular}

${ }^{*}$ Repeatability was defined as the possibility of returning to exactly the same sampling unit in future monitoring. 
Table 4. A comparison of selection of underwater spectral imaging systems as outlined by Lui et al.,2020 [75] including the Hy$\mathrm{Ri} / \mathrm{HyFi}$ arranged by cost.

\begin{tabular}{|c|c|c|c|c|c|c|c|}
\hline Model & Developer & $\begin{array}{c}\text { Spectral } \\
\text { Range/Bands }\end{array}$ & Resolution & $\begin{array}{l}\text { Spatial Imag- } \\
\text { ing }\end{array}$ & $\begin{array}{l}\text { Depth } \\
\text { Rating }\end{array}$ & $\begin{array}{c}\text { Cost } \\
(£)\end{array}$ & Notes \\
\hline Bi-Frost DSLR & Bristol University & $339-789 \mathrm{~nm} / 192$ & 18nm@450nm & Push-broom & $60 \mathrm{~m}$ & $\sim 5,000$ & \\
\hline TuLUMIS & $\begin{array}{c}\text { Liu et al. } 2018 \\
{[104]}\end{array}$ & $400-700 \mathrm{~nm} / 8$ & $>10 \mathrm{~nm}$ & Staring array & $2000 \mathrm{~m}$ & $\begin{array}{l}\sim 5210.00 \\
(\$ 6730)\end{array}$ & $\begin{array}{c}\text { UUV } \\
\text { mounted }\end{array}$ \\
\hline HyperDiver & $\begin{array}{c}\text { Chennu et al. } 2017 \\
{[76]}\end{array}$ & $400-900 \mathrm{~nm} / 480$ & $1.5 \mathrm{~nm}$ & Push-broom & $50 \mathrm{~m}$ & $\begin{array}{c}\sim 20,040 \\
(22,000 €)\end{array}$ & $\begin{array}{c}\text { Air } \\
\text { weight } \\
\sim 32 \mathrm{~kg}\end{array}$ \\
\hline LUMIS 2 & $\begin{array}{c}\text { Zawada et al. } \\
2010[105]\end{array}$ & $\begin{array}{c}460,522,582,678 \\
\mathrm{~nm} / 4\end{array}$ & $12.0-42.1 \mathrm{~nm}$ & Staring array* & $20 \mathrm{~m}$ & $\begin{array}{c}\sim 46470 \\
(\$ 60,000)\end{array}$ & $\begin{array}{c}{ }^{*} 4 \text { imagers } \\
\text { used }\end{array}$ \\
\hline U185 & Cubert Gmbh & $450-950 \mathrm{~nm} / 125$ & $8 \mathrm{~nm} @ 532 \mathrm{~nm}$ & Snapshot & $5 \mathrm{~m}$ & $\begin{array}{c}\sim 49,850 \\
(54,900 €)\end{array}$ & \\
\hline WaterCam & Sphere Optics & $450-950 \mathrm{~nm} / 138$ & 8 nm@532 nm & Snapshot & $5 \mathrm{~m}$ & $\begin{array}{c}\sim 49,850 \\
(54,900 €)\end{array}$ & \\
\hline UMSI & $\begin{array}{c}\text { Wu et al. } 2019 \\
{[106]}\end{array}$ & $400-700 \mathrm{~nm} / 31$ & $10 \mathrm{~nm}$ & Staring & $50 \mathrm{~m}$ & $\begin{array}{c}\sim 56170 \\
(\$ 72,800)\end{array}$ & \\
\hline UHI OV & Ecotone & $\begin{array}{c}380-750 \\
\mathrm{~nm} / 150-200\end{array}$ & $2.2-5.5 \mathrm{~nm}$ & Push-broom & $2000 \mathrm{~m}$ & $\begin{array}{c}\sim 57,800 \\
(\$ 75,000)\end{array}$ & $\begin{array}{c}\text { UUV } \\
\text { mounted }\end{array}$ \\
\hline
\end{tabular}

LUMIS: low-light-level underwater multispectral imaging system; UMSI: underwater spectral imaging system; HyRi/HyFi: Hyperspectral reflectance/fluorescence imager; TuLUMIS: tunable LED-based underwater multispectral imaging system; UHI OV: Ocean Vision. (Costs derived from manufacturers quotes with Exchange rate applied on 8/10/2020.

\section{Future Tools For Coral Monitoring? Low-cost Hyperspectral Imagers (Bi-Frost DSLR)}

A new type of hyperspectral imaging technology that utilises linear variable filter(s) (LVF) has recently emerged. A LVF is an optical filter whose bandpass windows varies continuously across its surface [107]. LVFs allow for lower cost imagers to be produced [107]. For example, LVFs have been integrated with consumer grade digital cameras to convert them into hyperspectral imagers [107]-[109]. The Bi-Frost [107] DSLR, reduces the financial burden of spectral imagers by up to $75 \%$. Using DSLR cameras offers key advantages as they are already well implemented in underwater photography (in both scientific \& hobbyist applications), making them affordable and accessible both in supply and use. Non-specialised personnel can access and use the technology with relatively little training, thus reducing dependency on highly skilled divers and marine scientists for surveying.

The Bi-Frost DSLR can be implemented in two operational modes: hyperspectral reflectance imaging (HyRi) and fluorescence imaging $(\mathrm{HyFi})$. These modes use the same Bi-Frost DSLR with the only difference being which lighting conditions are used for imaging; HyRi images under sunlight/white light and HyFi under ultraviolet (UV) produced by light emitting diodes (LEDs).

The HyRi mode collects reflectance data similar to that of traditional hyperspectral imaging conducted by underwater imagers and airbourne imagers as previously detailed.

The HyFi mode utilises UV LEDs (405 nm) (BlueRobotics, USA), to provide the illumination source required to excite fluorescence of photosynthetic Symbiodiniaceae and fluorescent proteins (FPs) [39]. As with other hyperspectral systems, laboratory pre-calibration with different coral species should be recorded to aid in the interpretation of field data [21], [41], [110]. 
The methodology for gathering $\mathrm{HyRi} / \mathrm{HyFi}$ data is similar to that of underwater photogrammetry. A delivery platform, such as a diver or UUV, translates the imager across a target scene in a single line for measurements on a colony scale, or a 'lawn mower' pattern for a reef scale [111] ensuring sufficient overlap between line intersects [63] (Figure 4).

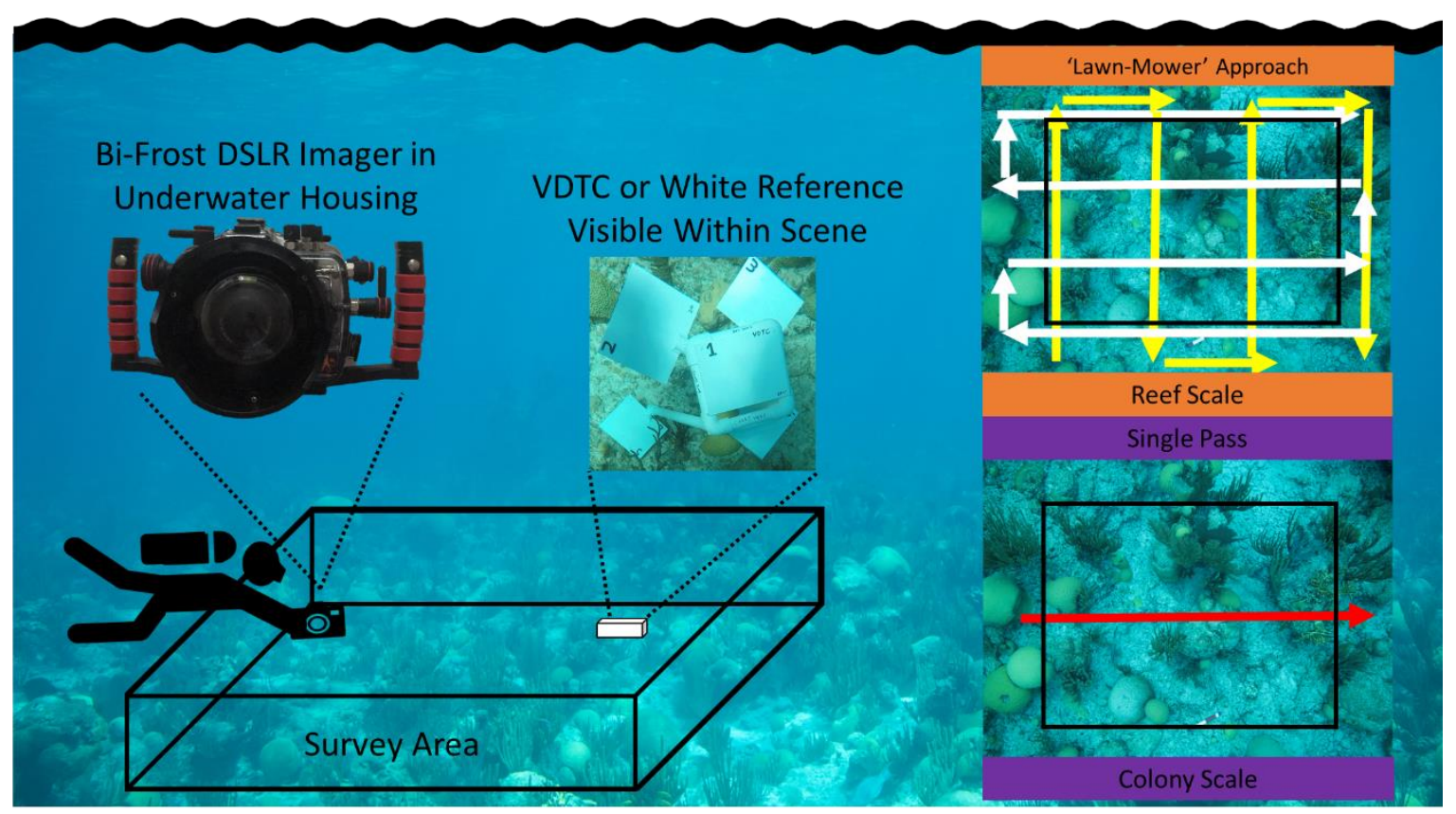

Figure 4. The survey method for Bi-frost DLSR hyperspectral imager, can either be conducted in 'lawn mower' approach [111] for reef scale surveys or a single line pass for colony scale surveys. To ensure sufficient coverage data the recorded area must exceed the target survey area. Water attenuations effects are corrected for by imaging white reference objects at various depths. These are variable depth target calibrators (VDTCs) which consists a series of white references at different depths) or a single white reference (only for correcting against incident light where variable depth is not considered) is required when imaging with Bi-Frost DSLR.

Spectral data can be extracted from the raw images generated from Bi-Frost cameras using photogrammetric approaches. Specifically, software was developed to interface with commercially available photogrammetric solutions (Photoscan 1.3.4, Agisoft, Russia). This software can produce hypercubes of intensity data having three spatial and one wavelength coordinate. In this way its use enables the construction of 3D models with full spectral information for each 3D surface point. The sizes of datasets are ultimately limited by the computing power required to run the reconstruction software. This approach generates camera positions in 3D space relative to the scene for each image taken. This in turn allows the accurate derivation of the correction factors needed to compensate for optical attenuation between the source and the detector. A single survey with a HyRi system therefore gathers spectral data (enabling for coral identification, zonation, physiological assessments) and 3D data (reef structure, rugosity), giving it twice the value.

\section{Concluding Remarks}

Current optical monitoring methods use a range of different approaches to answer the overly simplified question 'Is this coral reef healthy?'. Due to coral reefs being physically and ecologically complex ecosystems, each different technique offers a different piece of the puzzle shedding light on parameters pertaining to overall reef health and status.

The Earth's coral reefs face a difficult and challenging future. If they are to survive the impending onslaught, effective monitoring and assessment will be fundamental 
aiding their recovery. A wealth of technological know-how is already being applied to study coral reefs from the colony to global scale. Consequently, the understanding of the problem and its severity continues to improve. However, new tools are being developed to help facilitate all survey requirements across all scales. On the larger scale, satellites and aerial multispectral/ hyperspectral imaging provide greatest spatial coverage, at the tradeoff of reduced spatial resolution. For colony or reef scale surveys, HyRi can produce high spatial resolution but cannot replace remote systems. Rather, it is a tool to complement those assessments and provide ground truth data as to look at environments in closer detail. The use of in-situ imagers also enables areas to be studied where aerial imaging is not applicable, such as deep reefs or reefs with complex structures i.e. steep reef faces / walls and over hangs. Aerial based imaging is unsuitable for deep coral studies but tends to work best for mapping shallow lagoons and reef flats as these are within the depth threshold for this type of imaging (20m) [94].

In the near future, Bi-Frost DSLRs are predicted to be a powerful new addition in the diagnostic toolbox for coral health. The benefits of enabling rapid non-destructive and repeatable measurements [39] address many of the short comings of the current generation of UHI instruments. The 3D data obtained with a Bi-Frost DSLR can be used in many ways, making this single tool capable of recording data for several different diagnostic needs, from health to population surveys.

Author Contributions: Conceptualization, J.CC.D, J.T.; methodology, J.T.; software, D.M-S.; validation, J.C.C.D, J.T, D.M-S.; investigation, J.T.; writing-original draft preparation, J.T.; writing - review and editing, M.J.A, J.C.C.D, D.M-S, T.B.S.; supervision, J.C.C.D, T.B.S.; funding acquisition, T.B.S. All authors have read and agreed to the published version of the manuscript.

Funding: Pervioli Trust, Roddenberry foundation and Bristol Alumni Foundation.

Acknowledgments: We would like to acknowledge the editor Dr. Rupert Ormond for his guidance and wisdom to better focus the manuscript. We would also like to thank James Alexandroff for his continued support without which this project would not be possible.

Conflicts of Interest: The authors declare no conflict of interest.

\section{References}

[1] F. Moberg and C. Folke, “Ecological goods and services of coral reef ecosystems," Ecol. Econ., 1999.

[2] A. E. Douglas, “Coral bleaching - How and why?," Marine Pollution Bulletin, vol. 46, no. 4. Pergamon, pp. 385-392, 01-Apr-2003.

[3] P. J. Ralph, R. Gademann, and A. W. D. Larkum, “Zooxanthellae expelled from bleached corals at $33^{\circ} \mathrm{C}$ are photosynthetically competent," Mar. Ecol. Prog. Ser., 2001.

[4] B. L. Willis, C. A. Page, and E. A. Dinsdale, “Coral Disease on the Great Barrier Reef," Coral Heal. Dis., 2002.

[5] K. P. Sutherland, J. W. Porter, and C. Torres, "Disease and immunity in Caribbean and Indo-Pacific zooxanthellate corals," Marine Ecology Progress Series. 2004.

[6] J. R. Zaneveld et al., “Overfishing and nutrient pollution interact with temperature to disrupt coral reefs down to microbial scales," Nat. Commun., vol. 7, no. 1, pp. 1-12, Jun. 2016.

[7] P. J. Mumby, "The impact of exploiting grazers (Scaridae) on the dynamics of Caribbean coral reefs," Ecol. Appl., 2006.

[8] C. Mora, "A clear human footprint in the coral reefs of the Caribbean," Proc. R. Soc. B Biol. Sci., vol. 275, no. 1636, pp. 767-773, Apr. 2008.

[9] A. S. Wenger, K. E. Fabricius, G. P. Jones, and J. E. Brodie, “Effects of sedimentation, eutrophication, and chemical pollution on coral reef fishes," in Ecology of Fishes on Coral Reefs, C. Mora, Ed. Cambridge: Cambridge University Press, 2015, pp. $145-153$. 
[10] M. Kayal et al., "Predator Crown-of-Thorns Starfish (Acanthaster planci) Outbreak, Mass Mortality of Corals, and Cascading Effects on Reef Fish and Benthic Communities," PLoS One, vol. 7, no. 10, p. e47363, Oct. 2012.

[11] R. P. M. Bak and G. van Eys, “Predation of the sea urchin Diadema antillarum Philippi on living coral," Oecologia, vol. 20, no. 2, pp. 111-115, Jun. 1975.

[12] O. Hoegh-Guldberg, "Climate change, coral bleaching and the future of the world's coral reefs," Marine and Freshwater Research. 1999.

[13] O. Hoegh-Guldberg, L. Pendleton, and A. Kaup, "People and the changing nature of coral reefs," Regional Studies in Marine Science, vol. 30. Elsevier B.V., p. 100699, 01-Jul-2019.

[14] J. B. Lamb, J. D. True, S. Piromvaragorn, and B. L. Willis, “Scuba diving damage and intensity of tourist activities increases coral disease prevalence," Biol. Conserv., 2014.

[15] J. F. Bruno, I. M. Côté, and L. T. Toth, “Climate change, coral loss, and the curious case of the parrotfish paradigm: Why don't marine protected areas improve reef resilience?," Annual Review of Marine Science. 2019.

[16] J. Maynard et al., "Projections of climate conditions that increase coral disease susceptibility and pathogen abundance and virulence," Nat. Clim. Chang., 2015.

[17] R. van Woesik, S. Köksal, A. Ünal, C. W. Cacciapaglia, and C. J. Randall, "Predicting coral dynamics through climate change," Sci. Rep., vol. 8, no. 1, p. 17997, Dec. 2018.

[18] T. P. Hughes et al., “Global warming and recurrent mass bleaching of corals,” Nature, 2017.

[19] Queensland University of Technology (QUT), “Queensland's own rapid response tool for monitoring coral bleaching," 2017. [Online]. Available: https://www.qut.edu.au/news?news-id=122198. [Accessed: 12-Jun-2018].

[20] S. Sully, D. E. Burkepile, M. K. Donovan, G. Hodgson, and R. van Woesik, “A global analysis of coral bleaching over the past two decades," Nat. Commun., 2019.

[21] M. S. Roth and D. D. Deheyn, "Effects of cold stress and heat stress on coral fluorescence in reef-building corals," Sci. Rep., 2013.

[22] O. Hoegh-Guldberg et al., "Coral reefs under rapid climate change and ocean acidification.," Science (New York, N.Y.). 2007.

[23] P. W. Glynn, “Coral reef bleaching: ecological perspectives,” Coral Reefs, vol. 12, no. 1, pp. 1-17, Mar. 1993.

[24] C. S. Rogers, "The effect of shading on coral reef structure and function," J. Exp. Mar. Bio. Ecol., vol. 41, no. 3, pp. 269-288, Dec. 1979.

[25] C. Sheppard, S. Davy, G. Pilling, and N. Graham, The biology of coral reefs. Oxford University Press, 2017.

[26] S. F. Field, M. Y. Bulina, I. V. Kelmanson, J. P. Bielawski, and M. V. Matz, “Adaptive evolution of multicolored fluorescent proteins in reef-building corals," J. Mol. Evol., 2006.

[27] A. Antonius, "The 'band' diseases in coral reefs," The Fourth International Coral Reef Symposium. 1981.

[28] S. B. Galloway, A. W. Bruckner, and C. M. Woodley, "The Global Perspective on Incidence and Prevalence of Coral Diseases," 2009.

[29] D. Ruiz-Moreno et al., "Global coral disease prevalence associated with sea temperature anomalies and local factors," Dis. Aquat. Organ., 2012.

[30] E. A. Dinsdale, “Abundance of black-band disease on corals from one location on the Great Barrier Reef: a comparison with abundance in the Caribbean region," Proc. 9th Int. Coral Reef Symp., 2000.

[31] I. Miller and others, "Black band disease on the Great Barrier Reef," Coral Reefs-pages 15 58-, 1996.

[32] J. M. Cervino et al., "The Vibrio core group induces yellow band disease in Caribbean and Indo-Pacific reef-building corals," J. Appl. Microbiol., 2008.

[33] L. Bongiorni and B. Rinkevich, “The pink-blue spot syndrome in Acropora eurystoma (Eilat, Red Sea): A possible marker of stress?," Zoology, 2005. 
[34] J. Ravindran and C. Raghukumar, "Pink-line syndrome, a physiological crisis in the scleractinian coral Porites lutea," Mar. Biol., 2006.

[35] A. Antonius, "Black band disease infection experiments on hexacorals and octocorals," The Fifth International Coral Reef Congress. 1985.

[36] E. P. Green and A. W. Bruckner, "The significance of coral disease epizootiology for coral reef conservation," Biol. Conserv., 2000.

[37] C. V. Palmer, C. K. Modi, and L. D. Mydlarz, “Coral fluorescent proteins as antioxidants,” PLoS One, 2009.

[38] E. M. Muller and R. Van Woesik, “Caribbean coral diseases: Primary transmission or secondary infection?,” Glob. Chang. Biol., 2012.

[39] J. Teague, J. Willans, M. Allen, T. Scott, and J. Day, "Hyperspectral imaging as a tool for assessing coral health utilising natural fluorescence," J. Spectr. Imaging, 2019.

[40] H. Holden and E. LeDrew, "Spectral discrimination of healthy and non-healthy corals based on cluster analysis, principal components analysis, and derivative spectroscopy," Remote Sens. Environ., 1998.

[41] M. R. Myers, J. T. Hardy, C. H. Mazel, and P. Dustan, “Optical spectra and pigmentation of Caribbean reef corals and macroalgae," Coral Reefs, 1999.

[42] I. A. Leiper, U. E. Siebeck, N. J. Marshall, and S. R. Phinn, “Coral health monitoring: Linking coral colour and remote sensing techniques," Can. J. Remote Sens., 2009.

[43] J. S. Brown, "Absorption and fluorescence spectra of chlorophyll-proteins isolated from Euglena gracilis," BBA - Bioenerg., 1980.

[44] P. Falkowski and A. H. Knoll, Evolution of primary producers in the sea. 2007.

[45] N. O. Alieva et al., “Diversity and evolution of coral fluorescent proteins," PLoS One, 2008.

[46] T. S. Gil and J. Corredor, "Studies of photosynthetic pigments of zooxanthellae in Caribbean hermatypic corals," Reef Man. Proc. Fourth Int. Coral Reef Symp., 1981.

[47] A. A. Venn, M. A. Wilson, H. G. Trapido-Rosenthal, B. J. Keely, and A. E. Douglas, “The impact of coral bleaching on the pigment profile of the symbiotic alga, Symbiodinium," Plant, Cell Environ., 2006.

[48] M. Rodriguez-Lanetty, S. Harii, and O. Hoegh-Guldberg, "Early molecular responses of coral larvae to hyperthermal stress," Mol. Ecol., 2009.

[49] M. K. Desalvo et al., “Differential gene expression during thermal stress and bleaching in the Caribbean coral Montastraea faveolata," Mol. Ecol., 2008.

[50] J. Hill and C. Wilkinson, Methods for Ecological Monitoring of Coral Reefs. 2004.

[51] J. F. Bruno and E. R. Selig, "Regional decline of coral cover in the Indo-Pacific: Timing, extent, and subregional comparisons," PLoS One, 2007.

[52] C. A. Page et al., "Influence of marine reserves on coral disease prevalence," in Diseases of Aquatic Organisms, 2009.

[53] C. A. Page, S. N. Field, F. J. Pollock, J. B. Lamb, G. Shedrawi, and S. K. Wilson, “Assessing coral health and disease from digital photographs and in situ surveys," Environ. Monit. Assess., 2017.

[54] L. J. Raymundo, C. S. Couch, A. W. Bruckner, and C. D. Harvell, Coral Disease Handbook: Guidelines for Assessment, Monitoring \& Management. 2008.

[55] M. R. Patterson and N. J. Relles, “Autonomous Underwater Vehicles resurvey Bonaire: a new tool for coral reef management," in Proceedings of the 11th International Coral Reef Symposium, 2008.

[56] S. B. Williams et al., "Monitoring of benthic reference sites: Using an autonomous underwater vehicle," IEEE Robot. Autom. Mag., 2012.

[57] E. Bokolonga et al., "A compact multispectral image capture unit for deployment on drones," in Conference Record - IEEE 
Instrumentation and Measurement Technology Conference, 2016.

[58] O. Beijbom et al., "Towards automated annotation of benthic survey images: Variability of human experts and operational modes of automation," PLoS One, vol. 10, no. 7, Jul. 2015.

[59] I. D. Williams et al., "Leveraging automated image analysis tools to transform our capacity to assess status and trends on coral reefs," Front. Mar. Sci., 2019.

[60] U. E. Siebeck, N. J. Marshall, A. Klüter, and O. Hoegh-Guldberg, “Monitoring coral bleaching using a colour reference card," Coral Reefs, 2006.

[61] G. Winters, R. Holzman, A. Blekhman, S. Beer, and Y. Loya, "Photographic assessment of coral chlorophyll contents: Implications for ecophysiological studies and coral monitoring," J. Exp. Mar. Bio. Ecol., 2009.

[62] W. K. Fitt, F. K. McFarland, M. E. Warner, and G. C. Chilcoat, "Seasonal patterns of tissue biomass and densities of symbiotic dinoflagellates in reef corals and relation to coral bleaching," Limnol. Oceanogr., 2000.

[63] J. Teague and T. B. Scott, "Underwater Photogrammetry and 3D Reconstruction of Submerged Objects in Shallow Environments by ROV and Underwater GPS," J. Mar. Sci. Res. Technol., vol. 1, no. 005, 2017.

[64] I. Colomina and P. Molina, "Unmanned aerial systems for photogrammetry and remote sensing: A review," ISPRS Journal of Photogrammetry and Remote Sensing. 2014.

[65] D. T. I. Bayley and A. O. M. Mogg, "A protocol for the large-scale analysis of reefs using Structure from Motion photogrammetry," Methods Ecol. Evol., vol. 11, no. 11, pp. 1410-1420, Nov. 2020.

[66] J. D. Hedley and P. J. Mumby, "Biological and remote sensing perspectives of pigmentation in coral reef organisms," Adv. Mar. Biol., 2002.

[67] E. J. Hochberg and M. J. Atkinson, "Spectral discrimination of coral reef benthic communities," Coral Reefs, 2000.

[68] R. J. Jones, T. Kildea, and O. Hoegh-Guldberg, "PAM chlorophyll fluorometry: A new in situ technique for stress assessment in scleractinian corals, used to examine the effects of cyanide from cyanide fishing," Mar. Pollut. Bull., 1999.

[69] L. J. Chauka, G. Steinert, and M. S. P. Mtolera, "Influence of local environmental conditions and bleaching histories on the diversity and distribution of Symbiodinium in reef-building corals in Tanzania," African J. Mar. Sci., 2016.

[70] H. Kurihara, A. Takahashi, A. Reyes-Bermudez, and M. Hidaka, "Intraspecific variation in the response of the scleractinian coral Acropora digitifera to ocean acidification," Mar. Biol., 2018.

[71] C.-I. Chang, Hyperspectral imaging: techniques for spectral detection and classification, vol. 1. Springer Science \& Business Media, 2003.

[72] D. G. Zawada, “The Application of a Novel Multispectral Imaging System to the in vivo study of flourescent compounds in selected marine organisms," University of California, 2002.

[73] A. C. R. Gleason, R. P. Reid, and K. J. Voss, “Automated classification of underwater multispectral imagery for coral reef monitoring," in Oceans Conference Record (IEEE), 2007.

[74] O. Sture, M. Ludvigsen, F. Soreide, and L. M. S. Aas, "Autonomous underwater vehicles as a platform for underwater hyperspectral imaging," in OCEANS 2017 - Aberdeen, 2017.

[75] B. Liu et al., “Underwater hyperspectral imaging technology and its applications for detecting and mapping the seafloor: A review," Sensors (Switzerland). 2020.

[76] A. Chennu, P. Färber, G. De'ath, D. De Beer, and K. E. Fabricius, "A diver-operated hyperspectral imaging and topographic surveying system for automated mapping of benthic habitats," Sci. Rep., 2017.

[77] P. Maglione, "Very High Resolution optical satellites: An overview of the most commonly used," Am. J. Appl. Sci., vol. 13, no. 1, p. 91, 2016.

[78] G. Johnsen, M. Ludvigsen, A. Sørensen, and L. M. Sandvik Aas, "The use of underwater hyperspectral imaging deployed on remotely operated vehicles - methods and applications," IFAC-PapersOnLine, 2016. 
[79] G. Johnsen et al., "Underwater hyperspectral imagery to create biogeochemical maps of seafloor properties," in Subsea Optics and Imaging, 2013.

[80] D. R. Thompson et al., "Airborne mapping of benthic reflectance spectra with Bayesian linear mixtures," Remote Sens. Environ., 2017.

[81] R. Berkelmans, G. De'ath, S. Kininmonth, and W. J. Skirving, “A comparison of the 1998 and 2002 coral bleaching events on the Great Barrier Reef: Spatial correlation, patterns, and predictions," Coral Reefs. 2004.

[82] J. Boyd, "Drones survey the great barrier reef: Aided by AI, hyperspectral cameras can distinguish bleached from unbleached coral - [News]," IEEE Spectr., 2019.

[83] M. L. Clark, “Comparison of simulated hyperspectral HyspIRI and multispectral Landsat 8 and Sentinel-2 imagery for multi-seasonal, regional land-cover mapping," Remote Sens. Environ., vol. 200, pp. 311-325, Oct. 2017.

[84] B. E. Brown, R. P. Dunne, I. Ambarsari, M. D. A. Le Tissier, and U. Satapoomin, "Seasonal fluctuations in environmental factors and variations in symbiotic algae and chlorophyll pigments in four Indo-Pacific coral species," Mar. Ecol. Prog. Ser., 1999.

[85] A. Strong, C. Barrientos, C. Duda, and J. Sapper, “Improved satellite techniques for monitoring coral reef bleaching," Proc 8th Int Coral Reef Symp. 1997.

[86] G. Liu, A. E. Strong, W. J. Skirving, and L. F. Arzayus, “Overview of NOAA Coral Reef Watch Program's near-real-time satellite global coral bleaching monitoring activities," Proc. 10th Int. Coral Reef Symp., 2006.

[87] G. Liu et al., "Reef-scale thermal stress monitoring of coral ecosystems: New 5-km global products from NOAA coral reef watch," Remote Sens., 2014.

[88] K. E. Joyce, S. R. Phinn, C. M. Roelfsema, D. T. Neil, and W. C. Dennison, “Combining Landsat ETM+ and Reef Check classifications for mapping coral reefs: A critical assessment from the southern Great Barrier Reef, Australia," Coral Reefs, 2004.

[89] D. Palandro, S. Andréfouët, F. E. Muller-Karger, P. Dustan, C. Hu, and P. Hallock, "Detection of changes in coral reef communities using Landsat-5 TM and Landsat-7 ETM+ data," Can. J. Remote Sens., 2003.

[90] Y. Duan, Y. Liu, M. Li, M. Zhou, and Y. Yang, "Survey of reefs based on Landsat 8 operational land imager (OLI) images in the Nansha Islands, South China Sea," Acta Oceanol. Sin., 2016.

[91] D. J. Keith, B. A. Schaeffer, R. S. Lunetta, R. W. Gould, K. Rocha, and D. J. Cobb, “Remote sensing of selected water-quality indicators with the hyperspectral imager for the coastal ocean (HICO) sensor," Int. J. Remote Sens., vol. 35, no. 9, pp. 2927-2962, 2014.

[92] O. S. University, “What is HICO?,” 2015. [Online]. Available: http://hico.coas.oregonstate.edu/. [Accessed: 12-Jun-2018].

[93] R. P. Stumpf, K. Holderied, and M. Sinclair, “Determination of water depth with high-resolution satellite imagery over variable bottom types," Limnol. Oceanogr., vol. 48, no. 1part2, pp. 547-556, Jan. 2003.

[94] S. A. Foo and G. P. Asner, “Scaling up coral reef restoration using remote sensing technology," Front. Mar. Sci., 2019.

[95] E. Casella et al., "Mapping coral reefs using consumer-grade drones and structure from motion photogrammetry techniques," Coral Reefs, vol. 36, no. 1, pp. 269-275, Mar. 2017.

[96] E. J. Hochberg, S. A. Peltier, and S. Maritorena, “Trends and variability in spectral diffuse attenuation of coral reef waters," Coral Reefs, 2020.

[97] M. Takabayashi and O. Hoegh-Guldberg, "Ecological and physiological differences between two colour morphs of the coral Pocillopora damicornis," Mar. Biol., 1995.

[98] D. A. Anderson, R. A. Armstrong, and E. Weil, "Hyperspectral sensing of disease stress in the Caribbean reef-building coral, Orbicella faveolata - Perspectives for the field of coral disease monitoring," PLoS One, 2013.

[99] R. E. Johannes and W. J. Wiebe, “Method for Derterminations of Coral Tissue Biomass and Composition," Limnology and 
Oceanography. 1970.

[100] P. L. Jokiel et al., "Comparison of methods used to estimate coral cover in the Hawaiian Islands," Peer], 2015.

[101] W. Leujak and R. F. G. Ormond, “Comparative accuracy and efficiency of six coral community survey methods," J. Exp. Mar. Bio. Ecol., 2007.

[102] H. T. Kobryn, K. Wouters, L. E. Beckley, and T. Heege, “Ningaloo Reef: Shallow Marine Habitats Mapped Using a Hyperspectral Sensor," PLoS One, 2013.

[103] J. D. Hedley et al., “Remote sensing of coral reefs for monitoring and management: A review," Remote Sensing. 2016.

[104] H. Liu et al., "TuLUMIS - a tunable LED-based underwater multispectral imaging system," Opt. Express, 2018.

[105] D. G. Zawada and J. S. Jaffe, "Changes in the fluorescence of the Caribbean coral Montastraea faveolata during heat-induced bleaching ," Limnol. Oceanogr., 2010.

[106] C. Wu et al., "Development of an underwater multispectral imaging system based on narrowband color filters," in OCEANS 2018 MTS/IEEE Charleston, OCEAN 2018, 2019.

[107] O. Pust, “Innovative Filter Solutions for Hyperspectral Imaging," Opt. Photonik, vol. 11, no. 3, pp. $24-27$, Jun. 2016.

[108] I. G. E. Renhorn, D. Bergström, J. Hedborg, D. Letalick, and S. Möller, “High spatial resolution hyperspectral camera based on a linear variable filter," Opt. Eng., 2016.

[109] S. Song et al., "Low-cost hyper-spectral imaging system using a linear variable bandpass filter for agritech applications," Appl. Opt., vol. 59, no. 5, p. A167, Feb. 2020.

[110] C. H. Mazel, “Spectral measurements of fluorescence emission in Caribbean cnidarians," Mar. Ecol. Prog. Ser., 1995.

[111] J. Burns, D. Delparte, R. Gates, and M. Takabayashi, "Integrating structure-from-motion photogrammetry with geospatial software as a novel technique for quantifying 3D ecological characteristics of coral reefs," PeerJ, 2015. 